Maud S. Giorgi • Raphaël Arlettaz •

Frédéric Guillaume - Sébastien Nusslé • Carlo Ossola •

Peter Vogel · Philippe Christe

\title{
Causal mechanisms underlying host specificity in bat ectoparasites
}

Received: 13 July 2003 / Accepted: 27 November 2003 / Published online: 9 January 2004

C) Springer-Verlag 2004

\begin{abstract}
In parasites, host specificity may result either from restricted dispersal capacity or from fixed coevolutionary host-parasite adaptations. Knowledge of those proximal mechanisms leading to particular host specificity is fundamental to understand host-parasite interactions and potential coevolution of parasites and hosts. The relative importance of these two mechanisms was quantified through infection and cross-infection experiments using mites and bats as a model. Monospecific pools of parasitic mites (Spinturnix myoti and $S$. andegavinus) were subjected either to individual bats belonging to their traditional, native bat host species, or to another substitute host species within the same bat genus (Myotis). The two parasite species reacted differently to these treatments. $S$. myoti exhibited a clear preference for, and had a higher fitness on, its native host, Myotis myotis. In contrast, $S$. andegavinus showed no host choice, although its fitness was higher on its native host $M$. daubentoni. The causal mechanisms mediating host specificity can apparently differ within closely related host-parasite systems.
\end{abstract}

Keywords Host-parasite interactions · Coevolution · Spinturnix $\cdot$ Adaptive specialization hypothesis $\cdot$ Host preference

M. S. Giorgi $(\bowtie) \cdot$ F. Guillaume $\cdot$ S. Nusslé $\cdot$ C. Ossola P. Vogel · P. Christe

Department of Ecology and Evolution, University of Lausanne, Biology Building,

1015 Lausanne, Switzerland

e-mail: Maud.Giorgi@ie-zea.unil.ch

Tel.: +41-21-6924163

Fax: $+41-21-6924125$

R. Arlettaz

Zoological Institute-Conservation Biology, University of

Bern,

Baltzerstrasse 6,

3012 Bern, Switzerland

\section{Introduction}

Most parasites occur on a restricted number of hosts and show some evidence of specificity. Host specific parasites generally have a major host and a few less frequently used hosts (Poulin 1992; Tripet et al. 2002a); even generalists commonly show a preference for some species above others (Tripet and Richner 1997; Soler et al. 1999; Johnson et al. 2002). Such a drift towards greater host specificity is a common feature of many parasitic groups. Selection apparently tends to favour specialization of parasites to their local environment, i.e. their hosts (Combes 1991; Thompson 1994; Kawecki 1998; de Meeûs et al. 1998). In particular, host specialization appears to be promoted by host-dependent fitness tradeoffs dependent on the relative availability and predictability of hosts (Jaenike 1990; Thompson 1994; Combes 1995, 1997; Tripet and Richner 1997; Norton and De Lange 1999; McCoy et al. 2001). A parasite should specialize if the advantages of using one single host species in a profitable manner outweigh the benefits from interacting less profitably with several infrequent host species (Jaenike 1990; Norton and Carpenter 1998; McCoy et al. 2001). In other words, ephemeral or scarce hosts should promote parasite generalization (Tripet et al. 2002a), while parasites should specialize to their specific environmental conditions when hosts are abundant and predictable (Soler et al. 1999; Tripet et al. 2002b).

Host-parasite interactions, and thus host specificity, may be envisioned as taking place simultaneously at several different "host" levels. This is probably why such interactions are especially difficult to disentangle. In Spinturnicidae (ectoparasitic mites infesting colonial bats, Acari, Mesosotigmata), we have already investigated these interactions at two different host levels: individual (cost of parasitism: Giorgi et al. 2001) and population (Christe et al. 2000, 2003). In this study, we address hostparasite interactions at the community level and investigate the relative importance of different causal mechanisms underlying host specificity (Combes 1991; Poulin 
1992; Ward et al. 1998; Timms and Read 1999) within this host-parasite system.

Parasite specificity may be mediated by three main mechanisms. First, the dispersal capacity of parasite (first barrier to specificity) depends on the number of host species it can physically encounter during its life. This is linked to the parasite's intrinsic dispersal capacity (mobility and survival off the host) and upon the demographic and spatial properties of host populations (e.g. their mobility and geographic range; Gandon et al. 1996). In this respect, parasites may face difficulties invading several host taxa. Second, if parasites can disperse to another species, host preference (second barrier) will evolve if parasite fitness varies among hosts. If both conditions are fulfilled, the benefits to reduce host error outweigh the costs of developing host preference (Jaenike 1990; McCoy et al. 2001). Finally, when parasites disperse, they may have lost the ability to successfully transmit and establish a population on a novel host (last barrier). In this respect, highly specific parasites are expected to exhibit a higher reproductive success or survival on traditional, native host species than on less closely related ones (Norton and Carpenter 1998; Timms and Read 1999; Tompkins and Clayton 1999).

Numerous studies of host specificity have been performed on a variety of taxa from bacteria through parasitoids and nematodes to phytophagous and hematophagous insects. However, experiments that disentangle the relative importance of adaptive specialization versus dispersal ability have rarely been performed (Timms and Read 1999 but see de Meeûs et al. 1990, 1995; Becnel and Andreadis 1998; Kosoy et al. 2000; Thresher et al. 2000). In this study, we used a system with two parasite species belonging to the same genus (Spinturnix myoti, $S$. andegavinus) subjected to two related bat host species (Myotis myotis, M. daubentoni). With these two hostparasite pairs (M. myotis/S. myoti and M. daubentoni/S. andegavinus), we conducted two kinds of experiments: host preference experiments (dual host choice) and fitness experiments (infection and cross-infection). If adaptive specialization is responsible for host specificity, parasites should either prefer, or have a higher fitness on, traditional, native host species than on substitute ones. Thus, short-term and cross-infection experiments were performed to determine, respectively, the existence of host preference and the fitness of mites on traditional versus novel host species. If neither host preference nor parasite fitness differ between traditional and novel hosts, their host specificity should be governed by limited dispersal capacity and fixed long-term cospeciation events rather than by adaptive specialization. In this case, parasites should be capable of colonizing multiple hosts once the dispersal barrier is removed.

\section{Materials and methods}

\section{Study species}

This study was carried out during the breeding seasons of 1999 and 2000. Greater mouse-eared bats [Myotis myotis (Borkhausen, 1797)] were mist-netted at the entrance of two nursery colonies (church attics) in the upper Rhone Valley (Valais, Switzerland). Daubenton's bats [Myotis daubentoni (Leisler in Kuhl, 1819)] were mist-netted during their foraging flights above the Chamberonne River (Vaud, Switzerland). At capture, sex, age (juvenile, subadult, adult) and reproductive status (non-reproductive, pregnant, lactating) of bats were noted. Pregnancy and lactation were identified through abdominal palpation or gentle milk extraction, respectively. Weight and forearm length were measured to the nearest $0.1 \mathrm{~g}$ and $0.1 \mathrm{~mm}$, respectively. For ethical reasons, only subadult, non-reproductive females were taken and kept in captivity for laboratory experiments, under official authorization (Nature Conservation and Veterinary Offices of the cantons of Valais and Vaud).

Spinturnicidae mites [Spinturnix myoti Kolenati, 1856 and Spinturnix andegavinus (Kolenati, 1857); Acari, Mesostigmata, Spinturnicidae] are mobile ectoparasites, completing their entire lifecycle on bat wings and tail membranes (Rudnick 1960). The egg, pre-larval and first nymphal stages take place in the genital tract of the female mite. Pregnant females later give birth to male or female deuteronymphs, which already have an adult appearance (Evans 1968). All developmental stages are hematophagous, feeding on blood and lymph. As demonstrated earlier with $S$. myoti infesting $M$. myotis, these mites greatly affect time and energy budgets of their hosts: bat anti-parasite grooming activity as well as overall metabolism increase drastically with parasite load (Giorgi et al. 2001)

Host specificity in free-ranging bats

The traditional hosts of $S$. myoti across its range are M. myotis and M. blythii (Deunff 1977; Arlettaz, unpublished data). In Mediterranean populations, mouse-eared bats are typically cave-dwellers. They roost communally with $M$. blythii as well as with other cavernicolous bat species such as M. emarginatus, Miniopterus schreibersi and various Rhinolophus species (Estrada-Pena and Serra-Cobo 1991). All of these harbour different parasite species (Deunff 1977; Deunff and Beaucournu 1981). S. myoti may consequently occasionally encounter other potential host species. In contrast, $S$. andegavinus is specific to $M$. daubentoni, which forms monospecific nursery colonies. $M$. daubentoni is occasionally found in mixed roosts with Nyctalus noctula (which harbour Spinturnix acuminata; Deunff et al. 1997) and rarely with M. myotis. Thus, there are few opportunities for $S$. andegavinus encountering other bat species. Host preference may occur in wild populations because neither $S$. myoti nor $S$. andegavinus have been collected on the other bat species being studied here (Christe et al. 2000, 2003 and parasite phylogeny in progress).

Methods for handling, removing and counting parasites on bats

Mites used in these experiments were gently collected in the lab with soft forceps from the same populations as bats ( $S$. myoti from the $M$. myotis populations and $S$. andegavinus from the $M$. daubentoni population). S. myoti and S. andegavinus were always collected separately in order to prevent an interspecific parasite pool. A morphological inspection of the mites (according to Deunff 1977) confirmed that the mites collected from different host species populations belonged to distinct parasite species. Length and width of dorsal idiosoma were measured on males and females: body width was taken as the distance across the widest part of the idiosoma, while body length was measured from the mid-point of the anterior body margin to the mid-point of the posterior body 
Table 1 Morphometric measurements of the species of parasite (Spinturnix myoti and $S$ andegavinus) and host (Myotis myotis and $M$. daubentoni) involved in experiments. All values are mean \pm SE. Numbers in parentheses indicate sample sizes

\begin{tabular}{llcc}
\hline Parasite species & Sex & Body length $(\mathrm{mm})$ & Body width $(\mathrm{mm})$ \\
\hline S. myoti (43) & Female & $1.29 \pm 0.19$ & $1.00 \pm 0.13$ \\
& Male & $0.89 \pm 0.03$ & $0.74 \pm 0.02$ \\
S. andegavinus (33) & Female & $1.13 \pm 0.13$ & $0.93 \pm 0.10$ \\
& Male & $0.78 \pm 0.03$ & $0.66 \pm 0.03$
\end{tabular}

\begin{tabular}{llcc}
\hline Host species & Sex & Forearm length $(\mathrm{mm})$ & Weight $(\mathrm{g})$ \\
\hline M. myotis (20) & Female & $61.5 \pm 1.1$ & $25.3 \pm 0.9$ \\
M. daubentoni $(20)$ & Female & $38.2 \pm 0.2$ & $8.1 \pm 0.2$ \\
\hline
\end{tabular}

margin, thus excluding the gnathosoma (Rudnick 1960). All measurements were taken using Scion image software from a binocular microscope equipped with a camera. Males and females of $S$. andegavinus were each approximately $12 \%$ smaller than $S$. myoti (MANOVAs on body length and width with parasite species as factor; females: Pillai trace $=0.63, d f=1,33, P<0.001$; males: Pillai trace $=0.71, d f=1,41, P<0.001$; Table 1). Before each experiment, collected parasites were put in Petri dishes for no more than $30 \mathrm{~min}$ because neither $S$. myoti nor $S$. andegavinus can survive off the host for more than $3 \mathrm{~h}$ at ambient temperature (Fig. 1).

Mites live exclusively on bat wings and tail membranes and have never been found in or on the fur (Christe et al. 2003). Because wings and tail membranes of bats are entirely bare, parasites have no place to hide and visual inspection produced reliable counts of parasite infestation. The repeatability of parasite counts during the same capture was $0.99(n=52, P<0.001$; Christe et al. 2003). In addition, because $20 \mathrm{~s}$ maximum are necessary to count parasites on each bat, this method of counting was absolutely non-invasive. Similarly, because parasites were clearly visible on wings and tail membranes, collecting parasites with soft forceps prior to the experiment guaranteed that bats were entirely deparasitized.

\section{Host choice by parasites}

In order to test for the patterns of choice of the two parasite species, dual host choice experiments were designed as follows. A pair of deparasitized bats, consisting of one $M$. myotis and one $M$. daubentoni (any given individual was involved only twice in the experiments, once with each parasite species), was exposed to $S$.

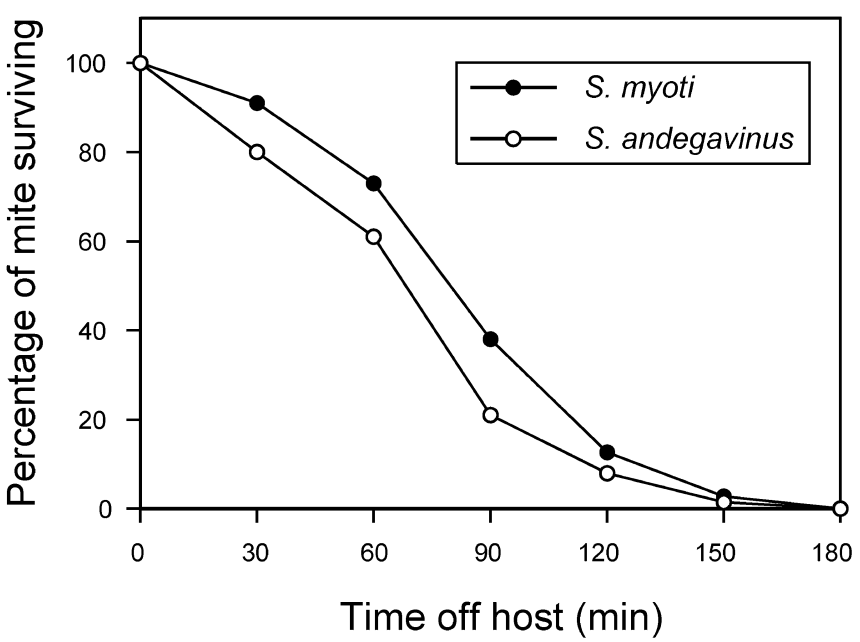

Fig. 1 Survival of ectoparasitic mites ( $n=40$ per curve) removed from their respective native host species and maintained separately, according to their original host species, in a shallow plastic cup at ambient temperature and humidity. Closed and open points are, respectively, data from Spinturnix andegavinus and S. myoti myoti ( $n=34$ trials) or $S$. andegavinus ( $n=31$ trials). For each replicate, 20 parasites $[13$ males or unsexed deuteronymphs (both categories being visually nearly indiscernible) plus 7 females] were deposited into a small Petri dish stuck on the centre of a small wooden box $(11 \times 8 \times 2.7 \mathrm{~cm})$. The experiment began only when every parasite was immobile and waiting for a host either in, or at the apex of, the Petri dish. At this time, the pair of bats was placed into the box, which was small enough to force close bat body contact and consequently direct parasite transfer from the Petri dish to the bats and from bat to bat. After $3 \mathrm{~h}$, the number of parasites present on each bat was counted. In a subsequent run, the same pair of bats was exposed to the other parasite species in the same way. After trial runs, bats were released into their colony of origin or reallocated to fitness experiments (see below). For analyses, the percentage of mites on a given host species was calculated from the final number of parasites found instead of the initial 20 mites, because in some trials a few additional parasites appeared (birth of deutonymphs) or disappeared (mean number \pm SE of parasites lost per run: S. myoti $0.44 \pm 0.08 ; S$. andegavinus $0.61 \pm 0.11$ ).

\section{Parasite fitness experiments}

Forty subadult female bats $(20 \mathrm{M}$. myotis and $20 \mathrm{M}$. daubentoni were captured as described above and kept separately in ca. $8 \mathrm{~m}^{3}$ semi-outdoor aviaries with ambient temperature and photoperiod for 5 days to acclimatize to captivity. Bats were fed ad libitum a mixed diet consisting of crickets (Acheta sp.) and mealworms (Tenebrio molitor).

After these 5 initial days, two replicates of four groups (two groups of $M$. myotis and two groups of $M$. daubentoni) of five bats each were formed and assigned to different aviaries (day 0 of experiment; Table 2). In each aviary, only one roost was provided to constrain the bats to rest together, allowing complete horizontal parasite transmission among bats as in nursery colonies in the wild. All possible combinations of bat infestations were created, including patterns of infection for each host-parasite species pair (i.e. parasite on its normal host) and cross-infection (Table 2). Since Jaenike (1996), Kristoffersen et al. (2001) and Tyler et al. (2001) have shown that density-dependent intraspecific competition among individual parasites may affect their fitness, initial intensity of infection was manipulated to reflect the mean number of parasites observed in the populations under study. In M. daubentoni, mite

Table 2 Partitioning of bats and parasites among the four semioutdoor aviaries (each table cell represents a distinct enclosure) for the 10-day fitness experiment. Species and number of bats and parasites are given. At day 0 (onset of experiment), either $15(S$. myoti) or seven ( $S$. andegavinus) mites were deposited onto each individual bat within a monospecific pool of five bats. Myotis is the bat genus, Spinturnix the parasite genus
Five Myotis myotis
75 Spinturnix myoti
Five $M$. daubentoni
Five $M$. myotis
375 S. myoti
35 S. andegavinus
Five $M$. daubentoni
35 S. andegavinus 
burdens on subadult females were (average \pm SE) $5.5 \pm 0.5 \mathrm{~S}$. andegavinus mites ( $n=150$ bats from 1999 to 2002; Giorgi et al., unpublished data) whereas $M$. myotis loads were $11.5 \pm 1.4$ S. myoti mites ( $n=216$ bats from 1998 to 1999; Christe et al. 2000). Consequently, we placed $15 \mathrm{~S}$. myoti mites on each individual deparasitized bat (i.e. totalling 75 mites per group), versus seven $S$. andegavinus mites per bat (totalling thus 35 mites in $S$. andegavinus aviaries; Table 2). Once the experiment was launched, parasite numbers were counted daily on every bat for 10 days. In addition, the percentage of remaining mites (with respect to the initial deposited number at day 0 ) was calculated at the end of the 10-day experiment in order to obtain demographic growth functions. Parasites not recovered from bats were assumed to have died in between, since neither $S$. myoti nor $S$. andegavinus can survive off the host for more than 3 hours at ambient temperature (Fig. 1). Demographic growth functions were averaged over the two replicate trials (except in Fig. 3). A 100\% growth function represents a constant mite population while a growth function, respectively, lower or higher than $100 \%$ represents a decreasing or increasing mite population.

\section{Statistical analyses}

Statistical analyses were performed using S-PLUS 2000 (MathSoft Inc 1988-1999, Seattle, Wash., USA). Prior to running statistical analyses, percentages were square-root arcsine transformed. Every variable was then tested for normality (Kolmogorov-Smirnov onesample test) and heteroscedasticity (one-way ANOVA); no variable deviated from these two assumptions. Because there was no significant year effect as regards host preference between the datasets of 1999 and 2000, data from both years were pooled together. As regards host choice experiments, paired $t$-tests were performed on the (transformed) percentage of mites on both host species. To compare mites' fitness, repeated-measures ANOVAs were applied on number of parasites recorded daily (repeated measure) over the duration of the experiments. Host species and replicate were assigned as between-factor terms, whilst time was used as the within-factor term. To compensate for a possible lack of compound symmetry in repeated measures ANOVAs, Huynh-Feldt adjustments of the degrees of freedom in the within-factor (time) analyses were accounted for (Gurevitch and Chester 1986; Glantz and Slinker 1991; Talan et al. 1996; Zar 1999). The adjusted degrees of freedom are directly reported in the text. All values reported are means \pm SE and all $P$-values are two-tailed.

\section{Results}

\section{Host choice by parasites}

S. myoti showed a highly significant preference for its own host, $M$. myotis (paired $t$-test: $t=11.68, d f=33, P<0.001$; Fig. 2). Preference was evident in 33 trials out of 34 , where at least $80 \%$ of mites had chosen M. myotis. In contrast, $S$. andegavinus showed no apparent host choice (paired $t$-test: $t=0.52, d f=30, P=0.604$; Fig. 2): in about half the trials (15 trials out of 31 ), the percentage of mites on both hosts was similar, indicating a random distribution between hosts.

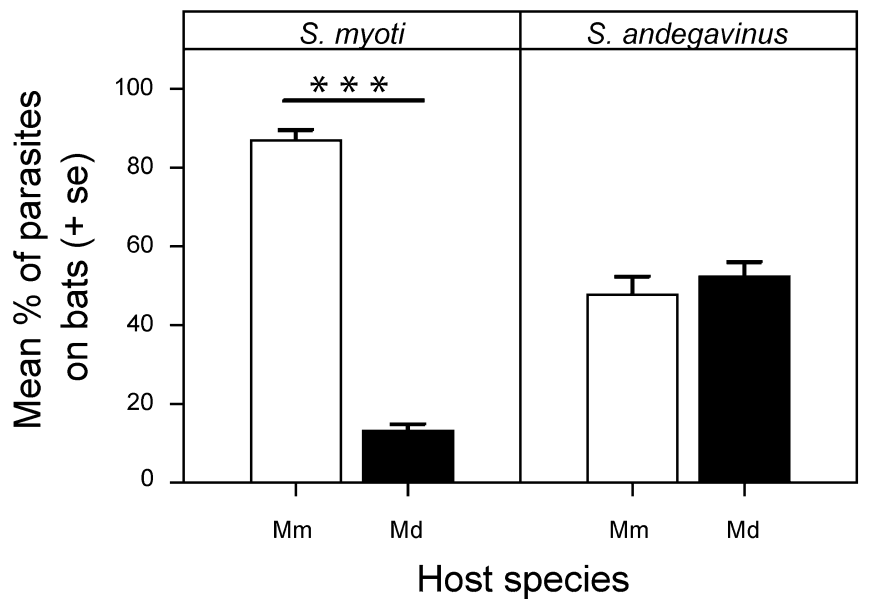

Fig. 2 Mean percentage (+SE) number of parasites (S. myoti and $S$. andegavinus) counted on each individual bat of a mixed pair of hosts after running a $3-\mathrm{h}$ dual host choice experiment. Twenty mites were placed in a small cup between the two bats at the onset of the experiment. Open bars percentage of mites on Myotis myotis; closed bars percentage of mites on M.daubentoni. Mm, Myotis myotis; Md, M. daubentoni. *** $P<0.001$

\section{Parasite fitness experiments}

\section{Spinturnix myoti}

The temporal pattern of fitness of $S$. myoti was explained by a single significant term, namely host species, whereas neither replicate nor time accounted significantly for the observed variation (repeated-measure ANOVA: $r^{2}=0.44$; host species: $F_{1,17}=42.40, P<0.001$; replicate: $F_{1,17}=2.82$, $P=0.11$; time: $\left.F_{1,19}=2.43, P=0.14\right)$. The mean demographic growth functions of $S$. myoti over the 10-day experimental period were $98 \%$ when the parasite was subjected to M. myotis, but $5 \%$ only when infesting the non-native host, $M$. daubentoni. In other words, the population of $S$. myoti on $M$. daubentoni had approached quasi-extinction at day 10 (Fig. 3). The demographic stability of $S$. myoti was noticeable on M. myotis; moreover, despite the fact that the recorded loss of individuals was not entirely compensated for by births, the population actually showed signs of reproduction on $M$. myotis (presence of unsclerified deuteronymphs).

\section{Spinturnix andegavinus}

In $S$. andegavinus, there was also a significant, albeit smaller effect of host species on fitness, whereas neither replicate nor time were significant (repeated ANOVA: $r^{2}=0.44$; host species: $F_{1,17}=124.63, P<0.001$; replicate: $F_{1,17}=0.23, P=0.64$; time: $F_{1,19}=0.92, P=0.35$ ). As above, the fitness of $S$. andegavinus on its native host species $(M$. daubentoni) was higher than on the substitute host ( $M$. myotis): nevertheless the demographic decline over time was much less dramatic in the latter case than for $S$. myoti on M. daubentoni (Fig. 3). Over the 10-day period, the 
Fig. 3 Outcome of the 10-day infection and cross-infection experiments. Two demographic growth functions were obtained from each of the four possible experimental combinations (two parasite species $\times$ two host species). The four experimental groups consisted of a monospecific pool of five individual bats each, associated with a predetermined number of parasites, and kept in separate aviaries (details about experimental design in Table 2)

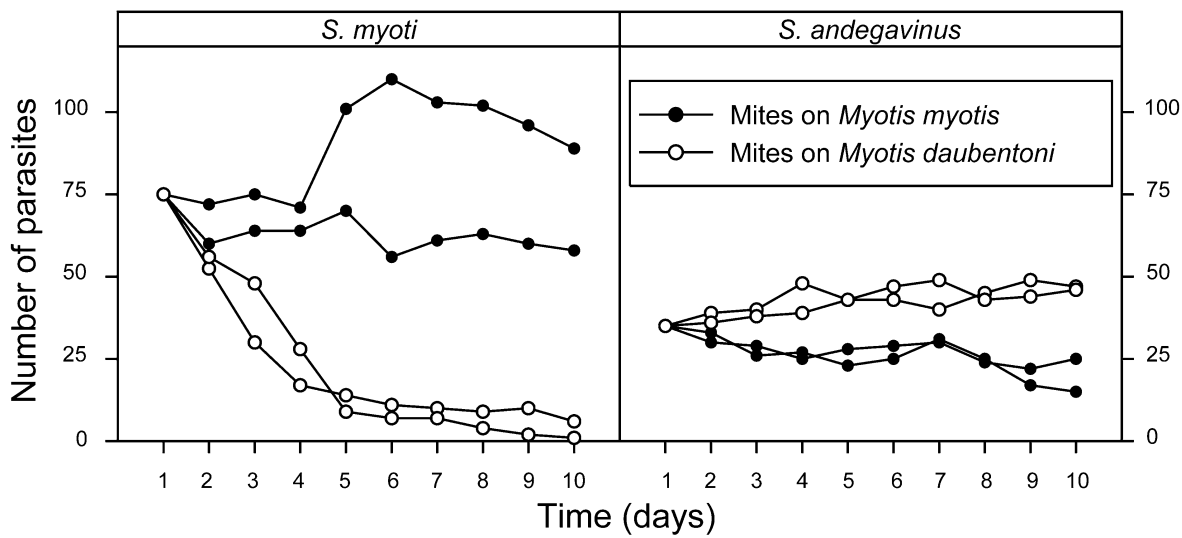

mean growth functions were $133 \%$, a strong increase, on M. daubentoni and 57\%, a marked decrease, on M. myotis.

\section{Discussion}

Host choice by parasites

In our experiments, the mite $S$. myoti exhibited a clear and immediate preference for its native bat host (M. myotis), while it tended to avoid the substitute host offered ( $M$. daubentoni). In contrast, $S$. andegavinus showed no initial choice for any of the two host species, which were seemingly colonized at random. Thus, differences in strength of host preference were detected between the two parasite species. Similar divergent patterns of host preference in closely-related species have been observed in various parasite taxa (de Meeûs et al. 1990, 1995; Le Brun et al. 1992; Du Preez and Kok 1997; Du Preez et al. 1997; Thresher et al. 2000)

As described above, preference should evolve according to parasite fitness and dispersal ability. In mites, difference in host preference should occur because the strength of one or both of these conditions (parasite population dynamics or parasite dispersal capacity) varies across parasite species. The first condition is satisfied in both species: mites survived and reproduced significantly better on the native than on the alien, substitute host. However, mortality was much more pronounced in $S$. myoti on $M$. daubentoni than in $S$. andegavinus on $M$. myotis. The second condition is also basically satisfied as both parasite species have the opportunity to switch host due to occasional contacts with other bat species (in maternity colonies as well as in winter colonies; Estrada-Pena and Serra-Cobo 1991). However, the frequency of such contacts differs for the two parasite species. Across its range, $S$. myoti has two frequent hosts, M. myotis and $M$. blythii, which are sister species (Deunff 1977; Ruedi and Mayer 2001; Arlettaz, unpublished data). These hosts are known to sometimes be in contact with some others cavernicolous bat species. In contrast, $S$. andegavinus is rarely mixed with bat species. This lower range of potential hosts as well as a lower fitness cost of substitute host species would thus explain the absence of host selection of $S$. andegavinus, while a drastic decrease on substitute host as well as more frequent opportunities of host switching for $S$. myoti promote the evolution of host preference in this species.

Cues for host selection

Given the huge mortality of parasites when off their host, it appears that both Spinturnix species have evolved strong mechanisms preventing being dropped from the host and/ or erroneous host transfer. Firstly, mites are difficult to remove from bat wings and tail membranes, to which they adhere strongly. Secondly, mites accidentally leaving their host towards an inanimate substrate quickly return to the host. Thirdly, parasites which have unexpectedly lost their host adopt, after a few seconds of searching, a hostwaiting posture with widely open legs pointing up towards any passing obviously aerial bodies. It is striking to notice the rapidity of the reaction elicited in a vagrant parasite. This points to very simple cues enabling the parasite to discriminate between an inappropriate substrate and a potential host. As shown by Sonenshine (1993), Cox et al. (1998), Devine et al. (2000) and Osterkamp et al. (1999), mites can use a mixture of vibrations, shadowing, $\mathrm{CO}_{2}$ concentration and others chemical signals to recognize their hosts. In the absence of appropriate tests, however, the stimuli involved in host species recognition in Spinturnix mites remain unknown. We hypothesize that subtle differences in the chemical signature of the hosts must be exploited by $S$. myoti and $S$. andegavinus when host choice is operated.

Parasite fitness with respect to host species

In this study, mites survived and reproduced significantly better on native than on alien substitute hosts. Adaptation to particular hosts is not surprising for permanent parasites of vertebrates. It has been described previously in other parasites such as syringophilid mites and swiftlet lice (Kethley 1971; Tompkins and Clayton 1999), which spend their entire lifecycle on the same type of host. We have to note here that, similar to the study by Tompkins and 
Clayton (1999), we restricted our fitness comparison to a 10-day experiment. This was due to logistic and ethical reasons: maintenance of wild-captured bats in captivity for long periods is both difficult and questionable. Yet, since parasite demographic growth on the native bat host was approximately equivalent to, or higher than, $100 \%$, we can reasonably consider our experimental conditions as representative of natural circumstances: in other words, a temporal prolongation of the experiments would probably not have altered the outcome of the tests.

As regards cross infections, it should be noticed that mortality was strikingly more pronounced for $S$. myoti on $M$. daubentoni than for $S$. andegavinus on M. myotis. For the former, there was a drop in parasite intensity from 15 to less than one mite per bat over 10 days. In contrast, $S$. andegavinus had a much higher level of survival on $M$. myotis. Differences in dispersal capacity leading to evolution of host preference (see above) may account for this huge difference. In addition, the fact that both parasite species showed few signs of reproduction (unsclerified mites that indicate freshly born individuals) on substitute hosts - whilst reproduction actually took place during infection experiments - support the hypothesis that mites are poorly adapted to substitute hosts.

Notwithstanding the quantitative difference in mortality when parasites were subjected to alien hosts, strong hostdependent fitness remains the most striking feature of our infection and cross-infection experiments. In our opinion, only long-term, fixed coevolutionary adaptations between the parasite and its host would lead to this pattern, revealing divergent evolutionary paths. In this context, the instantaneous preference shown by $S$. myoti might have been selected by host dependent fitness, which induces immediate, correct host choice via efficient host recognition cues. In other words, the benefits of reducing host selection error would tremendously outweigh the costs of developing new adaptations for a novel host (Jaenike 1990; McCoy et al. 2001).

\section{Conclusion}

In $S$. myoti, the causal mechanisms mediating host specificity appeared to be an intermediate dispersal capacity and species-specific adaptations of the parasite towards its host. In contrast, in S. andegavinus, despite a high specificity in the field, species-specific adaptations to the host have seemingly evolved to a lesser extent. We can conclude that current adaptive specializations maintain host specificity and may promote cospeciation events. The present study, carried out at the population and community levels, does not enable us to further infer conclusively about the selective pressures responsible for the potential coevolutionary adaptations within Spinturnicidae. Like in any evolutionary arms race, these adaptations probably proceed from reciprocal adjustments of parasite to host and host to parasite. In this respect, further investigations integrating micro-evolutionary (individual and population level; see Christe et al. 2000, 2003; Giorgi et al. 2001) and macro-evolutionary perspectives simultaneously (the present contribution and a cophylogenetic study of European bats and their parasites which is currently in progress) would provide decisive insights into the functional patterns of such host-parasite arms races.

Acknowledgements We are grateful to Névéna Basic, Brigitte Reutter and Sylvain Ursenbacher for help with fieldwork. We warmly thank Sara Helms Cahan for helpful comments and improving the English. This study was supported by a grant from the Swiss National Science Foundation to P.V., R.A. and P.C. (3100052584.97 and 3100-061450.00/1). The experiments comply with the current laws of the country in which the experiments were performed.

\section{References}

Becnel JJ, Andreadis TG (1998) Amblyospora salinaria n. sp. (Microsporidia: Amblyosporidae), parasite of Culex salinarius (Diptera: Culicidae): its life cycle stage in an intermediate host. J Invertebr Pathol 71:258-262

Christe P, Arlettaz R, Vogel P (2000) Variation in intensity of a parasitic mite (Spinturnix myoti) in relation to the reproductive cycle and immunocompetence of its bat host (Myotis myotis). Ecol Lett 3:207-212

Christe P, Giorgi MS, Vogel P, Arlettaz R (2003) Differential species-specific ectoparasitic mite intensities in two intimately coexisting sibling bat species: resource-mediated host attractiveness or parasite specialization? J Anim Ecol 72:866-872

Combes C (1991) Evolution of parasite life cycles. In: Toft CA, Aeschlimann A, Bolis L (eds) Parasite-host associations. Coexistence or conflict? Oxford University Press, London, pp $62-82$

Combes C (1995) Interactions durables: ecologie et évolution du parasitisme. Masson, Paris

Combes C (1997) Fitness of parasites - pathology and selection [Review]. Int J Parasitol 27:1-10

Cox R, Stewart PD, Macdonald DW (1998) The ectoparasites of the European badger, Meles meles, and the behavior of the hostspecific flea, Paraceras melis. J Insect Behav 12:245-265

Deunff J (1977) Observations on Spinturnicidae of Occidental Paleartic Region (Acarina, Mesostigmata) - specificity, distribution and repartition. Acarologia 18:602-616

Deunff J, Beaucournu JC (1981) Phenology and variations of dermecos in some species of Spinturnicidae (Acarina, Mesostigmata). Ann Parasitol 56:203-224

Deunff J, Keller A, Aellen V (1997) Redescription of Spinturnix punctata (Sundevall, 1833) (Acari, Mesostigmata, Spinturnicidae), a specific parasite of Barbastella barbastellus (Chiroptera, Vespertilionidae). Rev Suisse Zool 104:199-206

Devine GJ, Ingvarsdottir A, Mordue W, Pike AW, Pickett J, Duce I, Murdue AJ (2000) Salmon lice, Lepeophtheirus salmonis, exhibit specific chemotactic responses to semiochemicals originating from the salmonid, Salmo salar. J Chem Ecol 26:1833-1847

Du Preez LH, Kok DJ (1997) Supporting experimental evidence of host specificity among Southern African polystomes (Polystomatidae, Monogenea). Parasitol Res 83:558-562

Du Preez LH, Kok DJ, Seaman MT (1997) Host recognition behaviour of polystome oncomiracidia (Polystomatidae: Monogenea) in contact with natural and substitute hosts. J Afr Zool 111:47-55

Estrada-Pena A, Serra-Cobo J (1991) The acarinia and nycteribidia zones of Miniopterus scheibersi Kuhl (Mammalia: Chiroptera) in the northeast of Spain. Folia Parasitol 38:345-354

Evans GO (1968) The external morphology of the post-embryonic developmental stages of Spinturnix myoti Kol. Acarologia 4:589-608 
Gandon S, Capowiez Y, Dubois Y, Michalakis Y, Olivieri I (1996) Local adaptation and gene-for-gene coevolution in a metapopulation model. Proc R Soc Lond B Biol Sci 263:1003-1009

Giorgi MS, Arlettaz R, Christe P, Vogel P (2001) The energetic grooming costs imposed by a parasitic mite (Spinturnix myoti) upon its bat host (Myotis myotis). Proc R Soc Lond B Biol Sci 268:2071-2075

Glantz SA, Slinker BK (1991) Primer of applied regression and analysis of variance. McGraw-Hill, New York

Gurevitch J, Chester ST (1986) Analysis of repeated measures experiments. Ecology 67:251-255

Jaenike J (1990) Host specialization in phytophagous insects. Annu Rev Ecol Syst 21:243-273

Jaenike J (1996) Population-level consequences of parasite aggregation. Oikos 76:155-160

Johnson KP, Williams BL, Drown DM, Adams RJ, Clayton DH (2002) The population genetics of host specificity: genetic differentiation in dove lice (Insecta: Phthiraptera). Mol Ecol $11: 25-38$

Kawecki TJ (1998) Red queen meets Santa Rosalia—arms races and the evolution of host specialization in organisms with parasitic lifestyles. Am Nat 152:635-651

Kethley JB (1971) Population regulation in quill mites (Acarina: Syringophilidae). Ecology 52:1113-1118

Kosoy MY, Saito EK, Green D, Marston EL, Jones DC, Childs JE (2000) Experimental evidence of host specificity of Bartonella infection in rodents. Comp Immunol Microbiol Infect Dis 23:221-238

Kristoffersen AB, Lingjaerde OC, Stenseth NC, Shimada M (2001) Non-parametric modelling of nonlinear density dependence: a three-species host-parasitoid system. J Anim Ecol 70:10981098

Le Brun N, Renaud F, Berrebi P, Lambert A (1992) Hybrid zones and host-parasite relationships - effect on the evolution of parasitic specificity. Evolution 46:56-61

McCoy KD, Boulinier T, Tirard C, Michalakis Y (2001) Host specificity of a generalist parasite: genetic evidence of sympatric host races in the seabird tick Ixodes uriae. J Evol Biol 14:395-405

Meeûs T de, Renaud F, Gabrion C (1990) A model for studying isolation mechanisms in parasite populations - the genus Lepeophtheirus (Copepoda, Caligidae). J Exp Zool 254:207214

Meeûs T de, Hochberg ME, Renaud F (1995) Maintenance of two genetic entities by habitat selection. Evol Ecol 9:131-138

Meeûs T de, Michalakis Y, Renaud F (1998) Santa Rosalia revisited: Or why are there so many kinds of parasites in 'the garden of earthly delights'? Parasitol Today 14:10-13

Norton DA, Carpenter MA (1998) Mistletoes as parasites: host specificity and speciation. Trends Ecol Evol 13:101-105

Norton DA, De Lange PJ (1999) Host specificity in parasitic mistletoes (Loranthaceae) in New Zealand. Funct Ecol 13:552559
Osterkamp J, Wahl U, Schmalfuss G, Haas W (1999) Host-odour recognition in two tick species is coded in a blend of vertebrate volatiles. J Comp Physiol 185:59-67

Poulin R (1992) Evolutionary ecology of parasites. From individual to communities. Chapman \& Hall, London

Rudnick A (1960) A revision of the family Spinturnicidae. Univ Calif Publ Entomol 17:157-284

Ruedi M, Mayer F (2001) Molecular systematics of bats of the genus Myotis (Vespertilionidae) suggests deterministic ecomorphological convergences. Mol Phylogenet Evol 21:436-448

Soler JJ, Møller AP, Soler M (1999) A comparative study of host selection in the European cuckoo Cuculus canorus. Oecologia 118:265-276

Sonenshine DE (1993) Biology of ticks. Oxford University Press, New York

Talan MI, Kirov SA, Clow LA, Kosheleva NA (1996) Cold acclimation-associated changes in brown adipose tissue do not necessarily indicate an increase of nonshivering thermogenesis in C57BL/6 J mice. Physiol Behav 60:1285-1289

Thompson JN (1994) The coevolutionary process. University of Chicago Press, Chicago

Thresher RE, Werner M, Hoeg JT, Svane I, Glenner H, Murphy NE, Wittwer C (2000) Developing the options for managing marine pests: specificity trials on the parasitic castrator, Sacculina carcini, against the European crab, Carcinus maenas, and related species. J Exp Mar Biol Ecol 254:37-51

Timms R, Read AF (1999) What makes a specialist special? Trends Ecol Evol 14:333-334

Tompkins DM, Clayton DH (1999) Host resources govern the specificity of swiftlet lice: size matters. J Anim Ecol 68:489500

Tripet F, Richner H (1997) The coevolutionary potential of a 'generalist' parasite, the hen flea Ceratophyllus gallinae. Parasitology 115:419-427

Tripet F, Jacot A, Richner H (2002a) Larval competition affects the life histories and dispersal behavior of an avian ectoparasite. Ecology 83:935-945

Tripet F, Christe P, Møller AP (2002b) The importance of host spatial distribution for parasite specialization and speciation: a comparative study of bird fleas (Siphonaptera: Ceratophyllidae). J Anim Ecol 71:735-748

Tyler KM, Higgs PG, Matthews KR, Gull K (2001) Limitation of Trypanosoma brucei parasitaemia results from density-dependent parasite differentiation and parasite killing by the host immune response. Proc R Soc Lond B Biol Sci 268:2235-2243

Ward SA, Leather SR, Pickup J, Harrington R (1998) Mortality during dispersal and the cost of host-specificity in parasiteshow many aphids find hosts. J Anim Ecol 67:763-773

Zar JH (1999) Biostatistical analysis, 4th edn. Prentice-Hall, Upper Saddle River, USA 